\title{
PENGARUH KOMPENSASI DAN KEPEMIMPINAN TERHADAP KINERJA KARYAWAN PADA PT MARUKI INTERNASIONAL INDONESIA MAKASSAR
}

\author{
Ahmad Pramadanu, Syarifuddin \\ Fakultas Komunikasi dan Bisnis Universitas Telkom \\ Jalan Telekomunikasi No. 1, Bandung \\ ahmadpramadanu@student.telkomuniversity.ac.id
}

\section{Abstract}

\begin{abstract}
Effective compensation can help companies motivate and attract employees to always improve their performance. Leadership is an important part in an organization or company to achieve all the performance targets set by the company. The purpose of this study was to analyze and determine whether compensation and leadership have an effect on employee performance. This study is a descriptive and causal research because this study aims to analyze the relationship between variables that describe the results of research using quantitative methods. The sampling technique used in this study is probability sampling with simple random sampling, because the number of population is known, then in determining the number of samples using the Slovin formula, with the results of the sample involving 71 respondents. The data analysis technique used descriptive analysis and multiple linear regression analysis. The results of the descriptive analysis of the Compensation, Leadership and Employee Performance variables as a whole, the magnitude of the influence of Compensation and Leadership is $75.8 \%$ and the remaining $24.2 \%$ is influenced by other variables not examined in this study. Partially, compensation and leadership have a significant effect on employee performance at PT Maruki Internasional Indonesia Makassar.
\end{abstract}

Keywords: Compensation, Leadership, Employee Performance

\begin{abstract}
Abstrak
Kompensasi yang efektif dapat membantu perusahaan dalam memotivasi serta menarik karyawan untuk selalu meningkatkan kinerjanya. Kepemimpinan merupakan salah satu bagian penting dalam organisasi atau perusahaan untuk mencapai semua target kinerja yang ditetapkan perusahaan. Tujuan penelitian ini adalah untuk menganalisis dan mengetahui apakah kompensasi dan kepemimpinan berpengaruh terhadap Kinerja Karyawan. Penelitian ini merupakan penelitian deskriptif dan kausal karena penelitian ini bertujuan untuk menganalisis hubungan antara variable yang menggambarkan hasil dari penelitian dengan menggunakan metode kuantitatif. Teknik sampling yang digunakan dalam penelitian ini adalah probability sampling dengan simple random sampling, dikarenakan jumlah populasi diketahui maka dalam menentukan jumlah sampel menggunakan rumus Slovin, dengan hasil sampel melibatkan 71 orang responden. Teknik analisis data menggunakan analisis deskriptif dan analisis regresi linear berganda. Berdasarkan hasil analisis deskriptif variabel Kompensasi, Kepemipinan dan Kinerja Karyawan secara keseluruhan, besarnya pengaruh Kompensasi dan Kepemimpinan sebesar $75,8 \%$ dan sisanya $24,2 \%$ dipengaruhi oleh variabel lain yang tidak diteliti dalam penelitian ini. Secara parsial Kompensasi dan Kepemimpinan berpengaruh secara signifikan terhadap Kinerja Karyawan pada PT Maruki Internasional Indonesia Makassar.
\end{abstract}

Kata Kunci: Kompensasi, Kepemimpinan, Kinerja Karyawan

\section{Pendahuluan}

Dalam era persaingan usaha yang semakin ketat, manajemen menuntut kinerja karyawan untuk terus ditingkatkan, sehingga perusahaan bisa menang dalam persaingan. Menurut Hasibuan (2019:10) Manajemen sumber daya manusia adalah ilmu dan seni mengatur hubungan dan peranan tenaga kerja agar efektif dan efisien membantu terwujudnya tujuan perusahaan, karyawan, dan masyrakat. Untuk mengoptimalkan Sumber Daya Manusia (SDM) dalam organisasi perlu memperhatikan faktor-faktor yang mempengaruhi kinerja karyawan antara lain: 
Kepemimpinan yang diterapkan dalam organisasi tersebut. PT Maruki Internasional Indonesia sendiri memiliki 241 karyawan, dan dengan jumlah karyawan sebesar itu dibutuhkan menejemen yang baik oleh perusahaan, sehingga tercipta efesiensi dan efektifitas dalam mencapai tujuan organisasi. Sebagai perusahaan yang bergerak dibidang manufaktur PT Maruki Internasional Indonesia memiliki tantangan untuk mengelola tenaga kerjanya, baik dari segi kenyamanan dalam bekerja maupun kinerja karyawan itu sendiri.

Menurut Suwatno dan Priansa (2018:40) Manajemen sumber daya manusia (MSDM) adalah suatu bidang manajemen yang khusus mempelajari hubungan dan peranan manusia dalam organisasi perusahaan. Menurut Bintoro dan Daryanto (2017:15) menyatakan bahwa Manajemen sumber daya manusia, disingkat MSDM, adalah suatu ilmu atau cara bagaimana mengatur hubungan dan peranan sumber daya (tenaga kerja) yang dimiliki oleh individu secara efisien dan efektif serta dapat digunakan secara maksimal sehingga tercapai tujuan bersama perusahaan, karyawan dan masyarakat menjadi maksimal. Dalam mencapai tujuan perusahaan.

Hasil pra kuesioner dengan jumlah responden 30 karyawan terhadap Kinerja Karyawan, Kompensasi, dan kepemimpinan di PT Maruki Internasional Indonesia Untuk Kinerja Karyawan pada PT Maruki Internasional Indonesia di Makassar menyatakan sangat setuju sebagian besar juga masih sangat rendah yaitu dibawah 40 persen, meskipun dalam pertanyaan "Saya menghargai rekan kerja saya begitupun sebalikya mereka juga menghargai saya" mencapai 43,3\% presentase tersebut juga tergolong rendah. Melihat betapa penting peran sumber daya manusia bagi kelangsungan hidup perusahaan, yang juga bukan hanya sekedar asset tetapi juga sebagai mitra perusahaan yang menjadi penggerak jalannya aktivitas suatu organisasi atau perusahaan tersebut, yang kemudian organisasi atau suatu instansi harus bisa bersikap adil terhadap mitranya tersebut dengan memberikan imbalan yang sesuai atas kinerja yang telah dia berikan kepada perusahaan. Demikian juga sikap kepemimpinan suatu instansi memiliki peran yang penting yang dapat menggerakan dan juga memotivasi serta menginspirasi bawahannya untuk dapat mencapai tujuan organisasi yang telah ditetapkan. Untuk dapat mewujudkan hal tersebut dibutuhkan kinerja dan hubungan yang baik dan saling menguntungkan bagi pihak perusahaan maupun bagi pihak karyawan.

Untuk Kompensasi pada PT Maruki Internasional Indonesia di Makassar para karyawan menyatakan sangat setuju masih dibawah 40 persen hal ini hanya indicator pernyataan "Perusahaan memberikan jaminan keselamatan serta bentuk perlindungan seperti asuransi jiwa, asuransi kesehatan, asuransi kecelakaan dan lain-lain" Yang mendapatkan jawaban sangat setuju. Hal ini perlu menjadi acuan manajemen perusahaan untuk bisa ditingkatkan menjadi diatas 60 persen, karena dengan hasil yang di bawah 40 persen sangat berpengaruh terhadap kinerja karyawan dan juga diharapkan mampu melakukan pendekatan dengan memberikan motivasi terhadap setiap karyawan agar dapat memberikan hasil yang positif.

Untuk Kepemimpinan pada PT Maruki Internasional Indonesia di Makassar menyatakan sangat setuju juga masih sangat rendah, presentase paling tingginya masih 30\% sedangkan presentase terendahnya adalah $16,7 \%$, yaitu dalam indikator pertanyaan "Pimpinan selalu memberikan motivasi dan inspirasi dalam mencapai tujuan organisasi". Dengan melihat dari latar belakang dan data hasil prakuesioner di atas maka peneliti merasa tertarik dan perlu untuk mengetahui dan meneliti lebih lanjut tentang Kompensasi dan Kepemimpinan yang diterapkan di PT Maruki Internasional Indonesia di Makassar, dengan judul penelitian: "Pengaruh Kompensasi dan Kepemimpinan Terhadap Kinerja Karyawan Pada PT Maruki Internasional Indonesia Makassar".

Berdasarkan latar belakang yang telah diuraikan diatas, maka peneliti dapat didefenisikan beberapa rumusan masalah, sebagai berikut:

1. Bagaimana Kompensasi di PT Maruki Internasional Indonesia Makassar?

2. Bagaimana Kepemimpinan di PT Maruki Internasional Indonesia Makassar? 
3. Bagaimana Kinerja Karyawan di PT Maruki Internasional Indonesia Makassar?

4. Bagaimana Pengaruh Kompensasi dan Kepemimpinan terhadap Kinerja Karyawan PT Maruki Internasional Indonesia di Makassar baik secara parsial maupun simultan?

\section{Manajemen Sumber Daya Manusia}

Menurut Sedarmayanti, (2017:3) mengatakan bahwa manajemen sumber daya manusia (MSDM) merupakan suatu proses pemanfaatan SDM secara efektif dan efisien melalui kegiatan perencanaan, penggerakan, pengendalian semua nilai yang menjadi kekuatan manusia untuk mencapai tujuan.

\section{Kinerja Karyawan}

Menurut Anwar Prabu Mangkunegara dalam Sumali (2019:439) mengatakan bahwa pengertian kinerja adalah hasil kerja secara kualitas dan kuantitas yang dicapai oleh seorang pegawai dalam melaksanakan tugasnya sesuai dengan tanggung jawab yang diberikan kepadanya. Menurut Sutrisno (2016:151) kinerja adalah "sebagai hasil yang telah dicapai seseorang dari tingkah kerjanya dalam melaksanakan aktivitas kerja". Menurut Sinambela (2017:480) kinerja adalah pelaksanaan suatu pekerjaan dan penyempurnaan pekerjaan tersebut sesuai dengan tanggung jawabnya sehingga dapat mencapai hasil sesuai dengan yang diharapkan. Menurut Sinambela (2017:480) kinerja karyawan atau individu adalah sebagai kemampuan individu dalam melakukan sesuatu dengan keahlian tertentu.

\section{Kompensasi}

Menurut Hasibuan (2018) dalam Mulyapradana, Rosewati, dan Muafiq (2020:28) Kompensasi adalah pendapatan yang berbentuk uang, barang langsung atau tidak langsung yang diterima karyawan sebagai imbalan atas jasa yang diberikan kepada perusahaan. Sedangkan menurut Mulyapradana \& Hatta (2016:28) Kompensasi merupakan suatu hal yang diterima karyawan sebagai pengganti kontribusi atas pekerjaan yang mereka lakukan di perusahaan. salah satunya Upah atau gaji merupakan hal yang penting untuk semua orang, khususnya bagi mereka yang bekerja, Setiap pekerja berhak memperoleh penghasilan yang layak bagi kemanusiaan, yang dapat memenuhi kebutuhan hidupnya.

\section{Kepemimpinan}

Sutarto dalam Arianto (2018:263) mengatakan Kepemimpinan merupakan rangkaian kegiatan penataan berupa kemampuan mempengaruhi perilaku orang lain dalam situasi tertentu agar bersedia bekerja sama untuk mencapai tujuan yang telah ditetapkan.

Sedangkan menurut Hasibuan (2011:157) dalam Arianto (2018:263) mengatakan pemimpin adalah seseorang yang mempergunakan wewenang dan kepemimpinannya untuk mengarahkan orang lain serta bertanggung jawab atas pekerjaan orang tersebut dalam mencapai suatu tujuan. Hasibuan (2017:170) mengatakan bahwa kepemimpinan adalah cara seseorang mempengaruhi perilaku bawahannya, agar mau bekerja sama dan bekerja secara produktif untuk mencapai tujuan organisasi.

\section{Kerangka Pemikiran}

Kerangka pemikiran ini bertujuan untuk mengkaji bagaimana hubungan antara Kompensasi (X1) dan Kepemimpinan (X2) sebagai variable independen, dan Kinerja Karyawan $(Y)$ sebagai variebel dependen serta mengkaji bagaimana keterikatan Kompensasi dan Kepemimpinan berpengaruh secara signifikan terhadap kinerja karyawan pada PT Maruki Internasional Indonesia di Makassar.

Menurut Kasmir (2016:208) untuk mengukur kinerja dapat digunakan beberapa dimensi sebagai berikut:

1. Kualitas (Mutu)

2. Kuantitas (Jumlah)

3. Waktu (Jangka Waktu)

4. Penekanan Biaya

5. Pengawasan

6. Hubungan Antar Karyawan

Menurut Mondy dan Martocchio

(2016:247) kompensasi yang diberikan

perusahaan dibagi menjadi dua bagian yaitu:

1. Kompensasi Langsung (Direct

\section{Compensation)}

2. Kompensasi Tidak Langsung (Indirect Compensation)

Menurut Veitzhal Rivai (2018:53) seorang pemimpin harus memiliki 
kemampuan untuk mengimplementasikan empat dimensi berikut ini :

1. Kemampuan membangun kerjasama dan membina hubungan baik

2. Memiliki efektifitas dalam melakukan kegiatan apapun.

3. Mampu memimpin dengan partisipatif
4. Kemampuan mendelegasikan tugas atau waktu

Berdasarkan teori-teori di atas dapat diasumsikan bahwa Kompensasi dan Kepemimpinan berpengaruh terhadap Kinerja Karyawan yang digambarkan dalam kerangka pemikiran teoritis berikut:

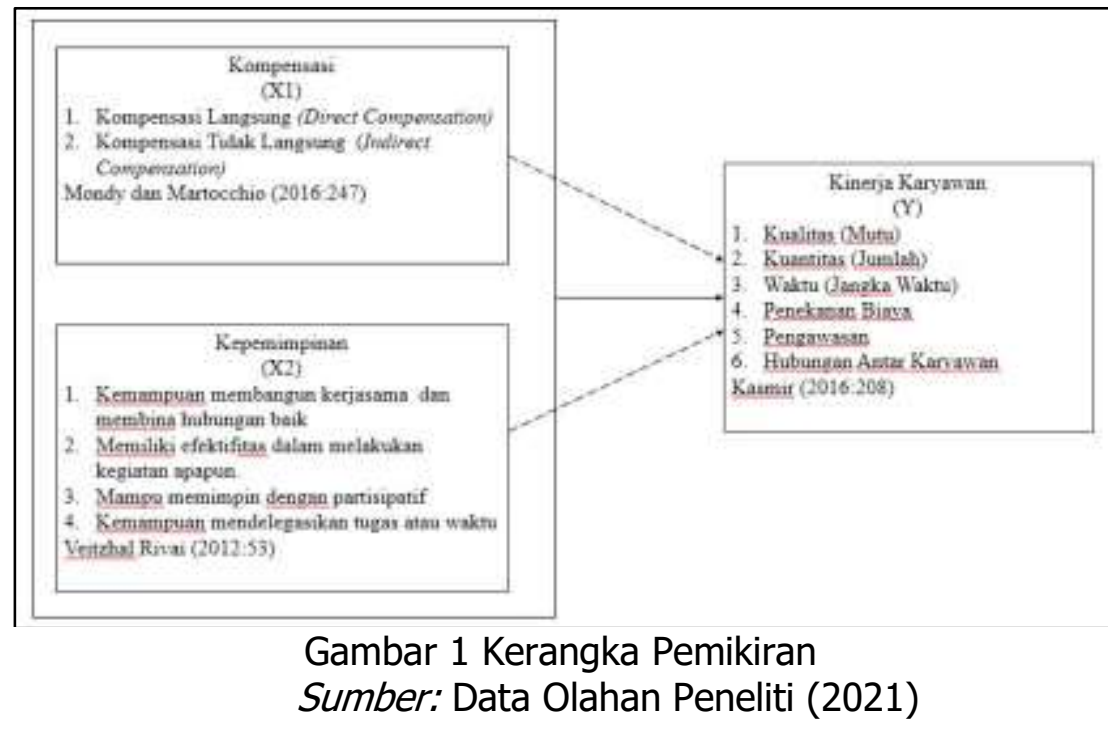

\section{Metode Penelitian}

Berdasarkan latar belakang dan rumusan masalah dapat dikatakan penelitian ini merupakan penelitian deskriptif dan kausal karena penelitian ini bertujuan untuk meenganalisis hubungan antara variable yang menggambarkan hasil dari penelitian. Penelitian ini menggunakan metode kuantitatif. Populasi dalam penelitian ini adalah karyawan PT Maruki Internasional Indonesia, yang mana jumlah karyawannya berdasarkan data dari perusahaan berjumlah 241 orang karyawan. Berdasarkan hasil hitung sampel, diperoleh angka 70,76 untuk jumlah sampel minimum, tetapi penulis membulatkannya menjadi 71 responden karyawan yang bekerja di PT Maruki Internasional Indonesia untuk mengurangi kesalahan pengisian kuesioner.

Teknik sampling yang digunakan dalam penelitian ini adalah probability sampling dengan simple random sampling yaitu teknik pengambilan sampel secara random atau tanpa pandang bulu. Pengumpulan data dilakukan berdasarkan sumbernya yaitu dengan menggunakan data primer dan data sekunder. Dalam penelitian ini, data primer menggunakan kuesioner dan sumber data diperoleh dari responden dan data sekunder didapatkan dari buku, E-Book, Internet, hasil riset, dan sumber informasi lainnya yang dianggap berkaitan dengan topik yang sedang diteliti.

\section{Teknik Analisis Data}

Teknik analisis data yang digunakan dalam penelitian ini adalah analisis deskriptif, uji asumsi klasik, analisis regresi linier berganda dan uji hipotesis. Uji asumsi klasik yang digunakan dalam penelitian ini meliputi uji normalitas, uji multikolinearitas, uji heteroskedastisitas. Uji hipotesis yang digunakan dalam penelitian ini meliputi uji t,uji $\mathrm{f}$ dan uji koefisien determinasi.

\section{Tahapan Penelitian}

Penelitian ini dilakukan dengan beberapa tahapan penelitian sebagai berikut: 


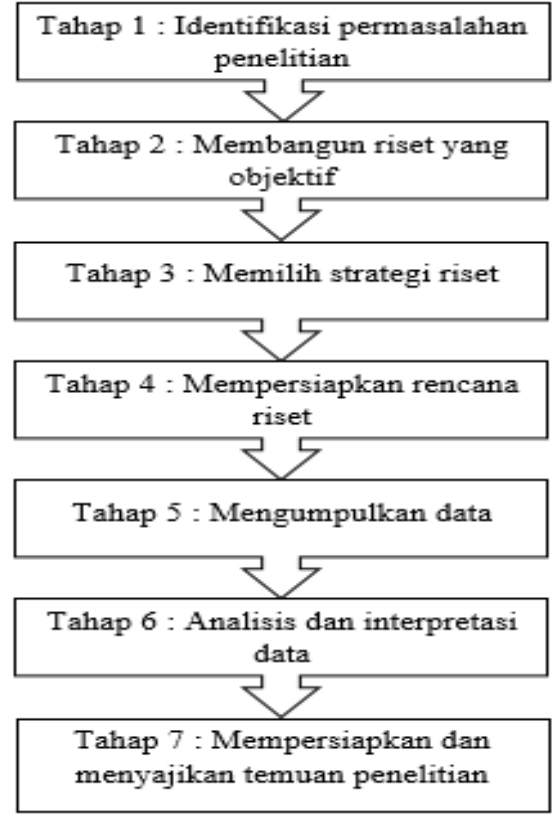

Gambar 2

Tahapan Penelitian

\section{Hasil Penelitian}

\section{Tanggapan Responden Mengenai Variabel Kompensasi}

Secara keseluruhan variabel Kompensasi $\left(\mathrm{X}_{1}\right)$ termasuk dalam kategori Tidak Baik dengan nilai persentase sebesar 48\%. Hal ini menunjukkan bahwa PT. Maruki Internasional Indonesia tidak cukup dalam melaksanakan ke dua dimensi variabel Kompensasi yaitu dengan kategori Tidak baik berdasarkan ke enam pernyataan diatas.

\section{Tanggapan Responden Mengenai Variabel Kepemimpinan}

Secara keseluruhan variabel Kepemimpinan $\left(X_{2}\right)$ termasuk dalam kategori Tidak Baik dengan nilai persentase sebesar 49\%. Hal ini menunjukkan bahwa PT Maruki Internasional Indonesia Tidak cukup baik dalam melaksanakan ke empat dimensi variabel Kepemimpinan dengan kategori tidak baik yaitu melalui pernyataan kuesioner diatas.

\section{Tanggapan Responden Mengenai Variabel Kinerja Karyawan}

Secara keseluruhan Kinerja Karyawan PT Maruki Internasional Indonesia menurut tanggapan responden berada pada kategori Tidak Baik dengan nilai persentase sebesar
$50 \%$. Hal ini menunjukkan bahwa Maruki tidak melaksanakan ke enam dimensi Kinerja Karyawan dengan baik.

\section{Uji Normalitas}

Tabel 1

Hasil Uji Normalitas

\begin{tabular}{|c|c|c|}
\hline & & $\begin{array}{l}\text { Unstandaroiz } \\
\text { ed Residual }\end{array}$ \\
\hline \multicolumn{2}{|l|}{$\mathrm{N}$} & 71 \\
\hline \multirow[t]{2}{*}{ Normal Parameters "s: } & Mean & .0000000 \\
\hline & $\begin{array}{l}\text { Std. } \\
\text { Deviation }\end{array}$ & 4.07232506 \\
\hline \multirow{3}{*}{$\begin{array}{l}\text { Most Extreme } \\
\text { Differences }\end{array}$} & Absolute & .060 \\
\hline & Postive & .039 \\
\hline & Negative & .006 \\
\hline \multicolumn{2}{|l|}{ Test Statistic } & .066 \\
\hline \multicolumn{2}{|l|}{ Asymp. Sig. (2-tailed) } & $200 \leqslant-1$ \\
\hline \multicolumn{3}{|c|}{ a. Test distribution is Normal. } \\
\hline \multicolumn{3}{|l|}{ b. Calculated from data. } \\
\hline \multicolumn{3}{|c|}{ c. Lilliefors Significance Correction. } \\
\hline
\end{tabular}

Berdasarkan tabel 1, 5 terlihat bahwa nilai Asymp.Sig. (2 tailed) adalah 0,200 dan lebih besar dari nilai signifikan $(0,05)$, dengan kata lain variabel residual tidak mengalami gangguan distribusi normal.sehingga data tersebut dapat digunakan untuk melakukan analisis regresi dan pengujian hipotesis.

Tabel 2

Hasil Uji Multikolinearitas

\begin{tabular}{|c|c|c|c|}
\hline Variabel & $\begin{array}{c}\text { Koefisien } \\
\text { Regresi } \\
(\beta)\end{array}$ & $\begin{array}{c}\text { Nilai } \\
\text { Tolerance }\end{array}$ & $\begin{array}{c}\text { Nilai } \\
\text { VIF }\end{array}$ \\
\hline Konstanta & $-0,493$ & & \\
\hline $\begin{array}{c}\text { Kompensasi } \\
\left(X_{1}\right)\end{array}$ & 1,087 & 0,446 & 2,240 \\
\hline $\begin{array}{c}\text { Kepemimpinan } \\
\left(X_{2}\right)\end{array}$ & 0,478 & 0,446 & 2,240 \\
\hline \multicolumn{3}{|c|}{}
\end{tabular}

\section{Uji Multikolinearitas}

Berdasarkan tabel 2, dapat dilihat bahwa nilai VIF 2,240<10 dan Tolerance 0,446 > 0,1 berarti tidak ditemukan masalah multikolinearitas dalam penelitian ini. 


\section{Uji Heteroskedastisitas}

Jika ada pola tertentu, seperti titik-titik yang membentuk pola tertentu yang teratur, maka terjadi heteroskedastisitas. Jika tidak pola yang jelas atau titik-titik menyebar di atas dan di bawah angka nol (0) pada sumbu Y, maka tidak terjadi heteroskedastisitas. Dapat dilihat bahwa diagram pencar tidak membentuk pola tertentu maka regresi tidak mengalami gangguan heteroskedastisitas.

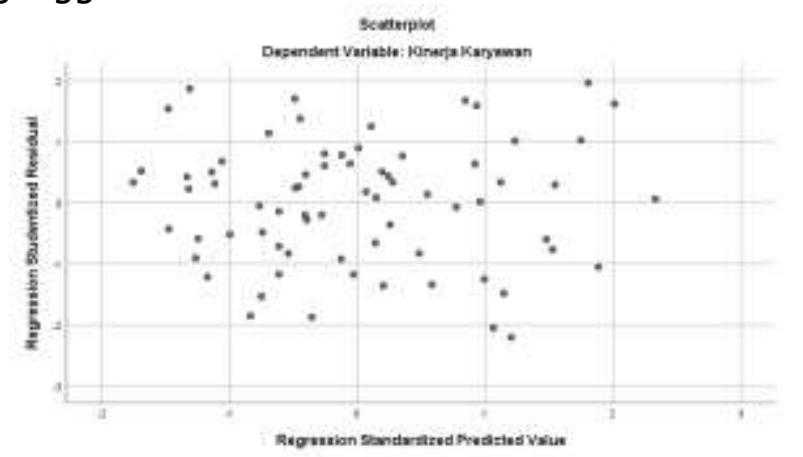

Gambar 3

Diagram Scatterplot

Analisis Regresi Linier Berganda

Tabel 3 Hasil Analisis Regresi Linier Berganda

\begin{tabular}{|c|c|c|c|}
\hline Variabel & $\begin{array}{c}\text { Nilai } \\
\text { Koefisien } \\
\text { Regresi } \\
(\beta)\end{array}$ & $\begin{array}{c}\text { Nilai T } \\
\text { Hitung }\end{array}$ & $\begin{array}{c}\text { Nilai } \\
\text { Sig. }\end{array}$ \\
\hline Konstanta & $-0,493$ & - & 0,837 \\
0,206 & 0,678 & 0,000 \\
\hline $\begin{array}{c}\text { Transformasi } \\
\text { Digital }\left(X_{1}\right)\end{array}$ & 1,087 & 6,731 & 0,000 \\
\hline $\begin{array}{c}\text { Kompetensi } \\
\left(X_{2}\right)\end{array}$ & 0,478 & 3,007 \\
\hline
\end{tabular}

Berdasarkan tabel 3, dapat diuraikan sebagai berikut:

1. Konstanta (a) $=-0,493$. Artinya, jika kompensasi $\left(X_{1}\right)$ dan Kepemimpinan $\left(X_{2}\right)$ nilainya adalah 0, maka Kinerja Karyawan nilainya $-0,493$.

2. Nilai koefisien regresi variabel Kompensasi $\left(b_{1}\right)$ bernilai positif, yaitu 1,087 . Artinya setiap peningkatan Kompensasi sebesar satu satuan, maka Kinerja Karyawan akan meningkat sebesar 1,087.

3. Nilai koefisien regresi variabel Kepemimpinan $\left(b_{2}\right)$ bernilai positif, yaitu 0,478 . Artinya setiap peningkatan Kepemimpinan sebesar satu satuan, maka Kinerja Karyawan akan meningkat sebesar 0,478 .
Berdasarkan persamaan tersebut dapat disimpulkan bahwa terdapat pengaruh yang positif dan berkaitan antara variabel Kompensasi dan Kepemimpinan dengan variabel Kinerja Karyawan. Artinya apabila variabel Kompensasi dan Kepemimpinan ditingkatkan maka variabel Kinerja Karyawan akan meningkat.

\section{$Y=-0,493+1,087 X_{1}+0,478 X_{2}$ Uji F (Secara Simultan)}

Tabel 4 Hasil Uji F (Secara Simultan)

\begin{tabular}{|c|c|c|c|c|c|c|}
\hline \multicolumn{6}{|c|}{ ANOVA $^{a}$} & \\
\hline \multicolumn{2}{|r|}{ Model } & $\begin{array}{l}\text { Sum of } \\
\text { Squares }\end{array}$ & $\mathrm{df}$ & $\begin{array}{c}\text { Mean } \\
\text { Square }\end{array}$ & $F$ & Sig. \\
\hline 1 & \begin{tabular}{|c} 
Regressi \\
on
\end{tabular} & $\begin{array}{r}3656.13 \\
3 \\
\end{array}$ & 2 & $\begin{array}{r}1828.0 \\
66 \\
\end{array}$ & 107.082 & .000 \\
\hline & Residual & $\begin{array}{r}1160.86 \\
8 \\
\end{array}$ & 68 & 17.072 & & \\
\hline & Total & $\begin{array}{r}4817.00 \\
1\end{array}$ & 70 & & & \\
\hline
\end{tabular}

Berdasarkan tabel 4, dapat diketahui $F_{\text {hitung }}>F_{\text {tabel }}(107.082>3,13)$ dan tingkat signifikansinya 0,000 $<0,05$. menunjukkan bahwa $\mathrm{H}_{0}$ ditolak dan $\mathrm{H}_{\mathrm{a}}$ diterima, artinya Variabel Independen yang terdiri dari Kompensasi dan Kepemimpinan secara bersama-sama memiliki pengaruh yang signifikan terhadap Kinerja Karyawan PT Maruki Internasional Indonesia.

Uji t (Secara Parsial)
\begin{tabular}{|c|c|c|c|}
\hline Variabel & $\begin{array}{c}\text { Nilai } \\
\text { Koefisien } \\
\text { Regresi } \\
(\beta)\end{array}$ & $\begin{array}{c}\text { Nilai T } \\
\text { Hitung }\end{array}$ & $\begin{array}{c}\text { Nilai } \\
\text { Sig. }\end{array}$ \\
\hline Konstanta & $-0,493$ & - & 0,837 \\
0,206 & 0,678 & 0,000 \\
\hline $\begin{array}{c}\text { Transformasi } \\
\text { Digital }\left(\mathrm{X}_{1}\right)\end{array}$ & 1,087 & 6,731 & 0,000 \\
\hline $\begin{array}{c}\text { Kompetensi } \\
\left(\mathrm{X}_{2}\right)\end{array}$ & 0,478 & 3 \\
\hline
\end{tabular}

Berdasarkan tabel 3, di atas dapat dilihat bahwa:

1. Variabel Kompensasi $\left(X_{1}\right)$ memiliki nilai $t_{\text {hitung }}$ $(6.678)>t_{\text {tabel }}(1,935)$ dan tingkat signifikansi $0,000<0,05$, maka $\mathrm{H}_{0}$ ditolak dan $H_{a}$ diterima. Artinya bahwa secara parsial terdapat pengaruh signifikan dari 
Kompensasi $\left(\mathrm{X}_{1}\right)$ terhadap Kinerja Karyawan (Y).

2. Variabel Kepemimpinan $\left(X_{2}\right)$ memiliki nilai $t_{\text {hitung }}(3.731)>t_{\text {tabel }}(1,935)$ dan tingkat signifikansi $0,000<0,05$, maka $\mathrm{H}_{0}$ ditolak dan $H_{a}$ diterima. Artinya bahwa secara parsial terdapat pengaruh signifikan dari Kepemimpinan $\left(X_{2}\right)$ terhadap Kinerja Karyawan (Y).

\section{Uji Koefisien Determinasi}

Tabel 5

Hasil Uji Koefisien Determinasi

\begin{tabular}{|c|c|c|c|r|}
\hline \multicolumn{5}{|c|}{ Model Summary } \\
\hline Model & $\mathrm{R}$ & $\begin{array}{c}\mathrm{R} \\
\text { Square }\end{array}$ & $\begin{array}{c}\text { Adjusted R } \\
\text { Square }\end{array}$ & $\begin{array}{c}\text { Std. Error of } \\
\text { the Estimate }\end{array}$ \\
\hline 1 &, $871^{\mathrm{a}}$ &, 759 &, 752 & 4.13178 \\
\hline
\end{tabular}

Berdasarkan tabel 3, menunjukkan bahwa nilai $R$ sebesar 0,871 dan $R$ square $\left(R^{2}\right)$ adalah 0,759. Angka tersebut digunakan untuk melihat besarnya pengaruh kualitas produk dan inovasi produk terhadap keunggulan bersaing secara simultan. Cara untuk menghitung $\mathrm{R}$ square menggunakan koefisien determinasi (KD) dengan menggunakan rumus sebagai berikut:

$$
\begin{gathered}
\text { KD }=r^{2} \times 100 \% \\
=(0,871)^{2} \times 100 \%=75,8 \%
\end{gathered}
$$

Angka tersebut menunjukkan koefisien determinasi (KD) sebesar 75,8\%. Hal ini menunjukkan bahwa pengaruh variabel independen (Kompensasi dan Kepemimpinan) terhadap variabel dependen yaitu Kinerja Karyawan adalah sebesar $75,8 \%$ sedangkan sisanya $24,2 \%$ dipengaruhi oleh faktor lain yang tidak diteliti dalam penelitian ini misalnya faktor Lingkungan Kerja.

\section{Kesimpulan}

Berdasarkan hasil penelitian dan pembahasan yang telah dikemukakan sebelumnya mengenai pengaruh Kompensasi dan Kepemimpinan terhadap Kinerja Karyawan PT Maruki Internasional Indonesia Makassar, dapat diambil beberapa kesimpulan yang diharapkan dapat memberikan jawaban terhadap permasalahan yang dirumuskan dalam penelitian ini adalah sebagai berikut:

1. Berdasarkan hasil analisis deskriptif bahwa Kompensasi PT Maruki Internasional Indonesia Makassar secara keseluruhan termasuk dalam kategori tidak baik.

2. Berdasarkan hasil analisis deskriptif bahwa Kepemimpinan PT Maruki Internasional Indonesia Makassar termasuk dalam kategori baik.

3. Berdasarkan hasil analisis deskriptif bahwa Kinerja Karyawan PT Maruki Internasional Indonesia Makassar termasuk dalam kategori tidak baik.

4. Kompensasi dan Kepemimpinan berpengaruh secara parsial dan simultan terhadap Kinerja Karyawan pada PT Maruki Internasional Indonesia Makassar.

\section{Saran}

Berdasarkan hasil kesimpulan yang telah diuraikan di atas, peneliti dapat memberikan beberapa saran yang kiranya dapat bermanfaat bagi pihak perusahaan PT Maruki Internasional Indonesia:

1. Disarankan agar PT Maruki Internasional Indonesia agar memperbaiki kebijakan reward management, sehingga karyawan terpacu dan beresemangat untuk bekerja lebih giat lagi.

2. Disarankan agar PT Maruki Internasional Indonesia dapat memberikan pelatihan kepemimpinan yang focus pada pengambilan keputusan.

3. Peneliti menyarankan agar perusahaan memberikan pelatihan team work kepada karyawan.

\section{Daftar Pustaka}

Arianto N. (2018). Pengaruh Kepemimpinan Terhadap Kinerja dan Kepuasan Kerja Karyawan Pada PT. Gada Rajawali Dunia, JENIUS: Jurnal Ilmiah, Manajemen Sumber Daya Manusia, Vol. 1, No. 3, 263.

Bintoro dan Daryanto. (2017). Manajemen Penilaian Kinerja Karyawan. Yokyakarta: Penerbit Grava Media 
Kasmir. (2016). Manajemen sumber daya manusia (teori dan praktek). Jakarta: Raja Grafindo Persada.

Mondy, R. W., \& Martocchio, J. J. (2016). Human Resource Management (Fourteenth). England: Pearson Education Limited.

Malayu S.P Hasibuan. (2019). Manajemen Sumber Daya Manusia. (Edisi Revisi). Jakarta: PT. Bumi Aksara.

Mulyapradana, A., T. Rosewati, dan F. Muafiq, (2020). Pengaruh Pemberian Kompensasi terhadap Kinerja Karyawan Hotel Dafam Kota Pekalongan. Widya Cipta: Jurnal Sekretari dan Manajemen, Volume 4 No. 1, 28.

Mulyapradana, A., \& Hatta, M. (2016). Jadi Karyawan Kaya: Genius Mengetahui \& Mengelola Hak Keuangan Karyawan (L. Sutinah (ed.); 1st ed.). Visimedia.

Suwatno dan D.J. Priansa. (2016). Manajemen SDM dalam Organisasi Publik dan Bisnis. Bandung: Alfabeta.

Sinambela, L P. (2017). Manajemen Sumber Daya Manusia. Membangun Tim yang Solid untuk Meningkatkan Kinerja. Jakarta. PT Bumi Aksara.

Sedarmayanti. (2017). Manajemen Sumber Daya Manusia. Bandung: Refika Aditama.

Sumali, A. (2019). Pengaruh Komunikasi Dan Disiplin Kerja Terhadap Kinerja

Guru SDN Parakan - Tangerang Selatan. Jurnal Ilmiah, Manajemen Sumber Daya Manusia, Vol. 2, 439

Sutrisno, E. (2016). Manajemen Sumber Daya Manusia. Jakarta: Kencana Prenada Media Group

Vietzhal, R. (2018). Perfomance Appraisal: Cara tepat dan mudah mengukur dan menilai kinerja karyawan dalam perusahaan. Edisi Ketiga. Raja Grafindo Persada, Jakarta. 